\title{
The Influence of Internal CSR Initiatives on the Organizational Citizenship Behaviors of Employees: An Abstract
}

\author{
Haw-Yi Liang, En-Yi Chou, and Jiun-Sheng Chris Lin
}

\begin{abstract}
Conducting CSR activities has been recognized as an effective way for corporations to build positive brand associations, which can lead to sustainable competitive advantage. However, extant CSR research has primarily focused on the consumers' perspectives and the shareholders' values; limited research has examined CSR from the employees' perspectives.

Although previous research has examined the influences of CSR on employees, they mainly focused on how organizations' external CSR activities affect employees' subjective perceptions and behavioral responses. Exploring the relationship between CSR and employees' outcomes from an internal marketing perspective has been generally overlooked. Therefore, this study aims to fill this research gap by exploring the effect of internal CSR initiatives on employees' attitude and organization-beneficial behaviors.

Drawing on social influence theory, this study develops and empirically tests a theoretical model that examines the impact of internal CSR initiatives (i.e., internal dissemination and management support of CSR) on employees' identification and attachment toward an organization, which ultimately leads to employees' organizational citizenship behaviors toward other employees and the organization. Data collected from 269 employees in companies actively involved in CSR initiatives was examined through structural equation modeling. Results and managerial implications were then discussed.
\end{abstract}

References Available Upon Request

H.-Y. Liang · E.-Y. Chou $(\bowtie) \cdot$ J.-S. C. Lin

National Taiwan University, Taipei City, Taiwan

e-mail: crystalhy.liang@gmail.com; tnajordan23@gmail.com; chrislin@ ntu.edu.tw

(C) Academy of Marketing Science 2019 